\title{
SYPHILITIC AORTITIS IN YOUNG ADULTS WITH SPECIAL REFERENCE TO A CONGENITAL ÆTIOLOGY
}

By STUART McDONALD, Junr. From the Department of Pathology, University of Durham College of Medicine.

In a previous communication (McDonald, I932*) the rarity of pathological case records of aortitis in lues tarda was pointed out, and an example of the condition in a patient aged 9 was described.

A further study of syphilitic aortitis encountered at autopsy in patients up to the age of thirty has been undertaken, and the following is an abstract of the clinical and pathological findings in II cases of this condition. Unless otherwise stated, the patients were admitted to the Royal Victoria Infirmary, Newcastleupon-Tyne. I am indebted to the Honorary Staff of this institution for access to case records, and to my colleagues in the Pathological Department for autopsy reports and material in some of the cases.

\section{CASE Records}

(I) J. M., a male, aged 22, and a Braille copyist by occupation, was admitted on 29.9.32. He complained of breathlessness and pain in the lower chest on exertion. These symptoms had become more severe lately but did not occur when he was at rest. Fourteen days before admission a very severe cough commenced.

Remote History.-On I9.I2.27 he was admitted to the V.D. department suffering from interstitial keratitis. The W.R. was positive. Between I9.12.27 and 27.9.32 he received $7^{\cdot} 2 \mathrm{gm}$. novarsenobillon $(0 \cdot 45 \mathrm{gm}$. dose) and gr. 40 of mercury (gr. I dose). The W.R. remained positive.

Family History.-Patient was an only child. Mother died from cerebral hæmorrhage, aged 48. Father alive and well.

- British Journal of Venereal Diseases, Vol. viii, p. 263. 


\section{BRITISH JOURNAL OF VENEREAL DISEASES}

Condition on Admission.-He was pale and breathless. Hutchinson's teeth present. Almost totally blind. Tibiæ thickened and rough with forward bowing.

Superficial cardiac dulness increased; apex beat in nipple line in fifth interspace. Loud "to and fro" pericardial friction. Apical systolic bruit. Pulse 108; tension good. B.P. I35/95. Resp. I20. Crepitations and moist sounds at left base. T. $97 \cdot 4^{\circ} \mathrm{F}$. Liver enlarged to two fingers' breadth below costal margin and somewhat tender. Electrocardiogram showed ventricular tachycardia.

Progress.-3.10.32. Patient very ill. P. I08, R. I40, T. $103^{\circ} \mathrm{F}$. Signs of consolidation at right base. Area of cardiac dulness increasing. Paracentesis pericardii yielded a large quantity of blood-stained fluid which clotted immediately. Death.

Clinical Diagnosis. - Acute pericarditis. Bronchopneumonia. Congenital syphilis.

Autopsy (Ref. 346/32).-Upper respiratory and digestive tracts healthy save for fibrosis of tonsils. Pleural sacs showed soft œdematous fibrous adhesions with patches of fibrinous exudate, and contained some pints of turbid fluid. A soft fibrino-hæmorrhagic exudate glued both layers of pericardial sac together, and about 20 c.c. of light yellow fluid was present. Main bronchi contained frothy mucus. Lung tissue was of a dull red colour throughout, and showed a moderate degree of œdema. There was partial collapse in both lower lobes, and there was extensive bronchopneumonia in both upper and lower lobes, a distinct hæmorrhagic appearance being present. Heart weighed I6 oz. Both sides were dilated and the left ventricle was slightly hypertrophied. The tricuspid and pulmonary valves were thin and delicate. The mitral leaflets were delicate but were covered with small firm gelatinous vegetations. Completely encircling the aorta and extending upwards from its origin for a distance of $2 \mathrm{~cm}$. was a typical syphilitic aortitis associated with much scarring. The upper margin ceased abruptly and the aorta above this was smooth. The condition extended down into the sinus of Valsalva around the coronary orifices; the latter were not extensively occluded. The myocardium was dull red in colour. There was no peritonitis and there were no special abnormalities in the gastro-intestinal tract. The spleen was 


\section{SYPHILITIC AORTITIS IN YOUNG ADULTS}

enlarged and weighed Io oz.; the appearances were those of chronic venous congestion. The liver showed similar appearances; small cavernous angeiomata were present. The left kidney weighed $9 \frac{1}{2} \mathrm{oz}$. and showed chronic venous congestion associated with the presence of several small simple infarctions. The right kidney was reduced to a thin filamentous opaque structure into which a small ureter ran. The other abdominal viscera and the testes and epididymes were healthy. Section of epiphyseal junctions showed nothing abnormal.

Histological Examination.-The appearances in the lungs, spleen, liver and left kidney confirmed the naked eye appearances. In the right kidney the normal architecture was completely disfigured. Diffuse fibrosis was present. Occasional partly differentiated glomeruli were seen, but there were numerous small areas of darkly staining endothelial cells apparently representing undifferentiated glomeruli. A striking feature was the presence of numerous nephrogenic tubules surrounded by whorls of delicate connective tissue. Tubules of adult type were also present; these were hypoplastic and contained hyaline casts and blood. There were numerous focal collections of histiocytes. A moderate degree of vascular thickening was present. The pelvis was represented by spaces lined by normal transitional epithelium.

The myocardium of the left auricle appeared to be healthy, as was the left coronary artery. The auricular portion of the mitral leaflets was swollen and gelatinous and showed an ingrowth of new-formed blood vessels. The vegetations were of simple rheumatic type but no Aschoff nodes were seen. In the myocardium of the left ventricle there were a few patchy areas of fibrosis. Early organising pericarditis was present generally. There was gelatinous thickening of the aortic valve associated with the ingrowth of new vessels, and recent simple vegetations were present. The attached margins of the cusps showed collagenous thickening associated with a definite vascular reaction and a moderate round cell infiltration. The adventitial coat of the aorta showed collagenous thickening associated with endarteritis and periarteritis. The media was invaded by branches of the vasa vasorum which were cuffed with lymphocytes and plasma cells. There had been extensive destruction of elastic tissue with replacement fibrosis. The intima 


\section{BRITISH JOURNAL OF VENEREAL DISEASES}

was raised up into thick fibrous plaques which showed hyaline change.

Pathological Diagnosis.-Acute pericarditis. Bronchopneumonia. Subacute rheumatic endocarditis with acute exacerbation. Generalised chronic venous congestion. Infarction of left kidney. Atresia of right kidney. Cavernous angeiomata of liver. Bilateral interstitial keratitis.

(2) E. B., a male, aged $2 \mathrm{I}$, was brought in dead on 9.8.32. He was an ice cream vendor by occupation.

Previous History.-He was noticed by a policeman to fall off his bicycle, and died almost immediately. No remote history was available.

Family History.-His father was the subject of locomotor ataxia.

Autopsy (Ref. 255/32).-The thymus was enlarged. Tonsils showed some chronic inflammatory enlargement; lymphoid tissue at the base of the tongue was hyperplastic. There was no pleurisy; lungs showed only chronic passive congestion and œdema. There was no pericarditis ; the heart was slightly enlarged. The right side was slightly dilated ; there was no endocarditis. The left side was normal in size ; the mitral valve was healthy. The right posterior aortic cusp showed chronic inflammatory thickening. The first part of the aorta, the arch, and the upper descending thoracic aorta showed elevated pearly plaques and longitudinal fissures, indicative of a gross degree of syphilitic aortitis. The orifices of the coronary arteries were occluded by the inflammatory process and a probe could only be inserted with great difficulty. Marked calcified atheromatous change was also present. The myocardium showed no special abnormalities.

There was no peritonitis and the abdominal viscera showed only chronic venous congestion modified by postmortem change. The stomach contained a large quantity of food. Nothing abnormal found in testes or epiphyseal junctions.

Histological Examination.-In the aorta there was gross collagenous thickening of the adventitia associated with marked peri- and endarteritis. There was gross destruction of the elastic tissue of the media which was being invaded by a strikingly large number of new vessels which were surrounded by massive collections of I86 


\section{SYPHILITIC AORTITIS IN YOUNG ADULTS}

lymphocytes and plasma cells, together with a fair number of eosinophils. The appearances suggested an active and progressive lesion. The intima was raised up into fibrous plaques which showed hyaline and atheromatous change. The other viscera showed no special changes other than chronic venous congestion.

Pathological Diagnosis.-Syphilitic aortitis with coronary occlusion. Generalised chronic venous congestion.

(3) C. B., aged I9 (sister of case 2). Domestic servant by occupation. I am indebted for details of this case to Dr. W. B. Purchase, H.M. Coroner for the Northern District of London, and to Dr. Hervey Wyatt, who performed the autopsy.

Clinical History.-On receipt of the news of her brother's death she collapsed and died immediately. Remote and family history as in case 2 .

Autopsy.-A gross degree of syphilitic aortitis was present, associated with narrowing of the coronary orifices, and involving approximately the same amount of aorta as in case 2. The heart valves were competent ; the myocardium was healthy. The stomach was full of food. There was no hyperplasia of thymus or of lymphoid tissue generally. There were no other gross abnormalities in the viscera; the genital organs were healthy. Histological examination was not undertaken.

Anatomical Diagnosis.-Syphilitic aortitis with coronary stenosis.

(4) J. C., a male, aged 24, and a commercial traveller by occupation, was admitted on 26.3.33. Some seven weeks before admission he had suffered an attack of "pleurisy" followed by a slight hæmoptysis. Since then he had been confined to bed and complained of dyspnœa and a harsh cough. During the last fourteen days before admission he also complained of severe upper epigastric pain.

Remote History.-Measles as a child. Pleurisy I926. Appendicectomy I927. Admitted to hospital 1930 complaining of pain in back and abdomen. At laparotomy a matted mass in the mesentery of the ileum was found. Sinus forceps were pushed in and blood spurted out. Twenty-four inches of gut were resected together with the mass. The pathological report stated the latter to consist of laminated blood clot.

Family History.-Father died of " consumption." 


\section{BRITISH JOURNAL OF VENEREAL DISEASES}

Condition on Examination.-General anasarca and slight cyanosis present. Signs of consolidation at lung bases present. Apex beat in sixth space $2 \frac{1}{2}$ inches outside midclavicular line. Area of cardiac dulness enlarged. Musical systolic murmur at apex radiating to axilla. Pulse regular but rapid and feeble. X-ray of chest showed a very large heart shadow.

Progress.-Between 30.3 .33 and 30.6 .33 the patient gradually became worse. There was progressive increase of œdema associated with failing output of urine and neither digitalis nor novarsurol relieved the œdema. There was continuous pain in the left chest and patient had severe attacks, during which he was greatly distressed, dyspnœic and cyanosed. Latterly there was copious blood-stained sputum and frequent vomiting. The pain was so severe as to necessitate the administration of morphine gr. i. daily. A series of electro-cardiograms were performed and there was evidence throughout of myocardial involvement; the termination of S in Lead III. being typical of coronary thrombosis. Death occurred on $3.7 \cdot 33$.

Clinical Diagnosis. - Coronary artery thrombosis. Congestive heart failure.

Autopsy (Ref. 232/33).--Marked ascites and hydropericardium. Dense fibrous adhesions in pleural sacs. The heart weighed $22 \frac{1}{2} \mathrm{oz}$. and was displaced towards the left. There were minute hæmorrhages at the base. Over the anterior aspect of the left ventricle midway between the apex and base there was a button-like ridge of fibrous tissue ; this was found to be a localised thickening in the wall of the left coronary artery. The right auricle was grossly dilated, as was the left side of the heart. There was no endocarditis. The first part of the aorta showed moderate atheromatous change, save for a small portion surrounding the right coronary orifice, where the appearances were indicative of syphilitic aortitis. On dissection of the right coronary artery the first $\frac{1}{2}$ inch was found to be obstructed by a mass of ante-mortem thrombus which was firmly attached to the wall. In the remainder of the vessel and in the left coronary artery nothing abnormal was found except the localised thickening of the latter noted above. The myocardium was fairly firm and was brownish-red in colour, save for numerous scattered whitish areas varying in size from a 


\section{SYPHILITIC AORTITIS IN YOUNG ADULTS}

pin's head to $\frac{1}{4}$ inch in area. The lungs showed advanced chronic venous congestion associated with multiple recent infarction. The other viscera showed no special abnormalities save chronic venous congestion, but there was terminal ante-mortem thrombosis of the splenic, superior mesenteric and portal veins.

Histological Examination.-Sections were cut to include the aorta and right coronary orifice, and the first $\frac{1}{2}$ inch of the right coronary artery. The aorta showed adventitial fibrosis, vascular invasion of the media with periarteritis and fibrous intimal thickening. There was periarteritis of the right coronary artery and the media showed changes characteristic of syphilis. The intima was thickened and covered with ante-mortem thrombus which showed hyaline changes. The thickened portion of the superficial branch of the left coronary artery showed fibrosis of the media and intima, but there was no cellular reaction.

There was a localised patchy fibrosis of the myocardium; the appearances suggested the scars of old infarctions. There was also considerable diffuse interstitial fibrosis.

Pathological Diagnosis.-Syphilitic aortitis with involvement of left coronary artery. Coronary thrombosis. Fibrosis of myocardium. Generalised chronic venous congestion with infarction of lung, and terminal thrombosis of splenic, superior mesenteric and portal veins.

(5) A. B., a single female, aged I9, was admitted to the City Hospital for Infectious Diseases on 26.3.32 as a case of scarlet fever. Three weeks before admission she had suffered from headache, vomiting, and sore throat associated with a generalised rash. No details of remote or family history available.

Condition on Admission.-There was a coarse bright scarlatiniform rash present generally; the tongue was covered with white fur. No special changes in throat. Temp. I00 $\cdot 2^{\circ} \mathrm{F}$., rising to $104^{\circ} \mathrm{F}$. Pulse 88. Resp. 26. Axillary and inguinal nodes enlarged and tender. Nil abnormal in chest or abdomen. Dick test negative. Discharged 29.3.32.

Clinical Diagnosis.-Exfoliative dermatitis.

She was admitted to the skin department on 9.4.32. The appearances were those of a well-nourished girl with facies suggestive of congenital syphilis, the nose being 


\section{BRITISH JOURNAL OF VENEREAL DISEASES}

saddle shaped, and the teeth spaced with broadening of their bases. There were scars below the nostril and on the lower lip. The skin generally was very dry and a process of exfoliation was evident-this being most marked on the face, neck and hands. Over the face the skin had a waxen appearance, being tightly bound to the underlying structures. The lips were dry and cracked, the tongue red and furred, and the buccal mucosa was tending to become septic. Whilst in hospital the patient was quite rational, but slept excessively and appeared to be drowsy most of the day. There was heavy albuminuria and the blood urea was raised. She was eventually transferred to a medical ward in a state of uræmia, where death occurred on I.5.32.

Autopsy (Ref. I33/32). The tonsils were swollen and acutely inflamed. There was septic change in the supratonsillar fossa on either side. Over the pillars of the fauces was a thin yellowish membrane which also involved the tip of the epiglottis and the epiglottic folds. The larynx and upper trachea were covered with a similar membrane. The pleural and pericardial sacs were healthy. The heart was slightly enlarged and showed some dilatation of the right side. There was no definite evidence of endocarditis, but the aortic cusps were thickened and opaque. The first 2 inches of the aorta showed the pearly plaques of syphilitic aortitis, and similar appearances were present at the commencement of the descending thoracic aorta. There was narrowing of the coronary orifices. The lungs showed chronic venous congestion with chronic bronchitis and early basal bronchopneumonia. There was no peritonitis; obsolete tabes mesenterica was present. The spleen showed subacute inflammatory enlargement. Chronic cystitis was present; the genital organs were healthy and of virgin type. The remaining viscera showed chronic venous congestion and intense cloudy swelling. There were no definite gross signs of nephritis.

Histological Examination.-The aorta showed gross adventitial fibrosis, peri- and endarteritis. The media was invaded by syphilitic granulation tissue and the intima was raised up into thickened fibrous plaques. There were also changes characteristic of syphilis in the right coronary artery. Apart from chronic venous congestion and fatty change the liver showed some peri- 


\section{SYPHILITIC AORTITIS IN YOUNG ADULTS}

portal fibrosis associated with infiltration by mononuclear cells. There was also fibrosis round the efferent veins of the lobules. The kidneys showed patchy areas of atrophic scarring in which many of the glomeruli were completely fibrosed; in other parts there was hyperplasia of nephrons. In addition some glomeruli showed endothelial proliferation with hæmorrhage within the tufts.

Pathological Diagnosis.-Exfoliative dermatitis. Acute pseudo-diphtheritic pharyngo-laryngitis. Bronchopneumonia. Chronic focal glomerulo-nephritis with acute exacerbation. Syphilitic aortitis with coronary involvement. Generalised chronic venous congestion.

(6) B. D., a single female, aged 26 , was admitted on I6.I.23. There was a history of breathlessness and palpitation for some months. She had had attacks of præcordial pain at night which lasted for a few minutes, and had caused fainting on occasion. During the last week before admission she complained of a burning epigastric pain which came on after meals. On admission the patient was very collapsed. Temp. $97^{\circ} \mathrm{F}$. Carotid pulse slow and feeble. There was extreme cyanosis. The area of cardiac dulness was enlarged; apex beat in fifth space. There was some epigastric tenderness. Family and remote history not obtained. She died on the day of admission.

Autopsy (Ref. 25/23). The serous cavities were healthy. The heart was enlarged with dilated right side. There was chronic thickening of the mitral and aortic cusps. Syphilitic aortitis limited to the first part of the aorta was present; there was marked stenosis of the coronary arteries, especially the left. The myocardium was mottled from acute toxic change. The apex of the right lung showed the scar of an obsolete tuberculous lesion; chronic bronchitis with terminal bronchopneumonia was present. There was an acute splenic tumour, and extreme toxic changes in the liver and kidneys were present. There was evidence of acute purulent salpingitis; no organism was detected. Histological examination was not undertaken.

Anatomical Diagnosis.-Syphilitic aortitis with coronary involvement. Bronchopneumonia. Acute salpingitis.

(7) C. G., a male, aged 28, was admitted on 27.3.I3. v.D.

I9I 


\section{BRITISH JOURNAL OF VENEREAL DISEASES}

During the week before admission he suffered from a severe cough with profuse expectoration, breathlessness, palpitation and swelling of the feet. He had been passing very little urine.

Remote History.-During the last two years there had been a severe chronic cough which occurred in spasms and left him cyanosed. He had been addicted to alcohol and gave a history of both syphilis and gonorrhoa. The parents were deceased; cause of death unknown.

On examination the patient was in great præcordial pain. Pulse II2; regular. Systolic B.P. I50. Apex beat normal. Double mitral and aortic murmur at apex ; systolic murmur conducted out to axilla. Rhonchi at lung bases. Heavy albuminuria. The patient was treated with digitalis and purgatives, but the odema persisted, and one week after admission there were two attacks of hæmoptysis. Death occurred on 30.4.I3.

Clinical Diagnosis.-Aortic regurgitation.

Autopsy (Ref. 137/13).- -Slight jaundice and marked œdema of legs present. Peritoneal sac contained a large amount of bile-stained fluid. The pleural sacs were almost obliterated by œdematous fibrous adhesions but contained a small amount of blood-stained fluid. The heart was grossly enlarged and weighed 191 oz. There was no pericarditis. There was gross dilatation of the right auricle and the right appendage contained antemortem thrombus. The right ventricle was markedly hypertrophied; there was no endocarditis on the right side. The myocardium of the left ventricle was thickened, glossy and œdematous ; the endocardium was thick and opaque. Mitral valve was healthy. Aortic valve was incompetent; the valve cusps were thickened and retracted and the right posterior cusp showed a large chronic vegetation. The first part of the aorta was the seat of a gross degree of syphilitic aortitis ; coronary stenosis was present but the arteries themselves were healthy. The inflammatory change extended round the arch and for about $1 \frac{1}{2}$ inches into the descending aorta. The lungs showed advanced chronic venous congestion; there was complete old-standing infarction of the upper lobe. In the basal portion of both lungs there were multiple more recent infarcts. The remaining viscera showed advanced chronic venous congestion. Histological examination was not undertaken. 


\section{SYPHILITIC AORTITIS IN YOUNG ADULTS}

Anatomical Diagnosis.-Syphilitic aortitis and aortic endocarditis with coronary stenosis. Generalised chronic venous congestion. Infarction of lungs.

(8) R. McC., a male, aged 30, was admitted on 25.9.3r. $\mathrm{He}$ was in a practically moribund condition, being cyanosed with almost imperceptible pulse. He complained of pain in the epigastrium, and there was some upper right rectus rigidity. There was a vague history of peptic ulcer ; no other information obtained. He died shortly after admission.

Clinical Diagnosis.-Ruptured duodenal ulcer.

Autopsy (Ref. 334/3r).- - Serous membranes healthy. The heart was enlarged with marked dilatation of the right side ; there being slight hypertrophy of the right ventricle. No endocarditis on right side. Left side dilated; the ventricle contained some ante-mortem thrombus, and there was a patch of subepicardial fibrosis at the apex. Mitral valve healthy. Aortic cusps thickened and opaque. The first $\frac{1}{2}$ inch of the aorta was thickened and showed white opaque patches and furrows, the appearances being characteristic of syphilitic aortitis. The coronary orifices were markedly stenosed ; the right being almost pinpoint. There was interstitial fibrosis of the myocardium. The remaining viscera showed chronic venous congestion; there was no evidence of peptic ulceration. Histological examination was not undertaken.

Anatomical Diagnosis.-Syphilitic aortitis with coronary occlusion. Fibrosis of myocardium. Generalised chronic venous congestion.

(9) W. F., a male, aged 29, was admitted to the Pensions Hospital, Newcastle-upon-Tyne, on I.3.25. He complained of dyspnœa and epigastric pain. There was a history of rheumatic fever seven years before admission. He was cyanosed with a faint icteric tinge of the skin. Corrigan's pulse associated with aortic diastolic and mitral systolic murmurs was present. Urine: few pus cells; albumen + ; fair number of granular casts. One month later he developed recurrent hæmoptysis and from this time till death on 21.4.25 the patient was febrile, very dyspnœic, and suffered from a left pleural effusion.

Clinical Diagnosis.-Aortic regurgitation.

Autopsy (Ref. 174/25).- There was no peritonitis. Bilateral acute fibrinous pleurisy present. The lungs 


\section{BRITISH JOURNAL OF VENEREAL DISEASES}

showed chronic venous congestion associated with the presence of multiple hæmorrhagic infarcts of considerable standing ; some of the latter showed early suppurative change. The heart weighed $55 \mathrm{oz}$. and was a typical cor bovinum. The right side was greatly dilated and hypertrophied; there was no endocarditis. The left side was dilated. Along the line of contact of the mitral cusps were recent simple vegetations. The aortic valve was incompetent; the cusps were thickened and opaque and showed similar vegetations. The myocardium showed fatty degeneration. The first part of the aorta showed well-marked syphilitic aortitis; the coronary orifices were patent. The remaining viscera showed only advanced chronic venous congestion. Histological examination was not undertaken.

Anatomical Diagnosis.-Syphilitic aortitis with aortic endocarditis. Acute simple endocarditis. Generalised chronic venous congestion with pulmonary infarction.

(Io) H. M., a female, aged 30, was admitted on 26.12.33. She complained of pain in the right upper chest of three months' duration. During the last month there had been pain in the left chest. Latterly, the sputum had been blood tinged and she complained of slight cough and breathlessness. On examination the patient was anæmic; there was no cyanosis. The teeth were foul. There was some impairment of movement of the left chest associated with dulness in the upper chest on this side. There was absolute dulness over the left lower chest and breath sounds were absent at the left base. There was tubular breathing, whispering pectoriloquy, and ægophony over a 2-inch area between the lower part of the vertebral border of the left scapula and the spine. Paracentesis thoracis on the left side yielded a small quantity of clear straw-coloured fluid. The right lung appeared to be healthy, and nothing abnormal was found on examination of the cardio-vascular system. On 30.I2.33 the patient coughed up some pints of blood and died in a few minutes.

Clinical Diagnosis.-Pulmonary tuberculosis.

Limited Autopsy (Ref. 477/33). On opening the chest the left lung was found to be collapsed, and the left pleural sac contained a small quantity of blood-stained fluid. On section the left lung showed a patchy bronchopneumonia. The right pleural sac was healthy; the 


\section{SYPHILITIC AORTITIS IN YOUNG ADULTS}

lung showed an extreme degree of emphysema. The first part of the aorta showed a moderate degree of atheroma, and in addition the pearly plaques of syphilitic aortitis were present. From the under surface of the aortic arch projected a saccular aneurysm about $I$ inch in diameter, which communicated with the aorta through a $\frac{1}{2}$ inch aperture. The sac was almost completely filled with laminated thrombus but rupture into the left bronchus had occurred. A positive W.R. was obtained from blood taken at the autopsy.

Histological Examination.-In the adventitia of the aorta there was endarteritis of vasa vasorum associated with intense perivascular cuffing. The media was extensively invaded with syphilitic granulation tissue and the intima was raised up into fibrohyaline plaques. The appearances suggested an active and progressive lesion.

Pathological Diagnosis.-Syphilitic aortitis. Aneurysm of aortic arch with rupture into bronchus. Bronchopneumonia.

(II) H. P., a female, aged 20, was brought in dead on 30.6.I9. She was a prostitute of Italian extraction, and there was a definite history of primary syphilis. No other clinical history was obtainable save that death took place during sexual congress.

Unfortunately the autopsy notes of this case have been lost but the heart was preserved as a museum specimen $\left(I_{15 / I}\right)$. The organ was not specially enlarged but there was some hypertrophy of the left ventricle. The first part of the aorta showed a gross degree of syphilitic scarring which extended into the sinus of Valsalva. The coronary orifices were narrowed to such an extent as to give the appearance of complete occlusion. The aortic orifice was stenosed and the valve cusps were thickened and opaque from chronic inflammatory change. Histological examination was not undertaken.

Anatomical Diagnosis.-Syphilitic aortitis with chronic aortic endocarditis. Coronary occlusion.

\section{Discussion}

In an endeavour to subdivide these cases into congenital and acquired groups one is met with the difficulty that in some instances the available data are insufficient 


\section{BRITISH JOURNAL OF VENEREAL DISEASES}

for this purpose, if the criteria which were mentioned in my previous communication be strictly adhered to.

These may be summarised as follows : (I) clinical history with special reference to family history ; (2) physical signs of lues tarda ; (3) symptom complex suggestive of aortic disease, especially if associated with an accentuated aortic second sound; (4) positive W.R. ; (5) positive orthodiagraphic findings ; (6) certain abnormal electrocardiographic findings ; (7) alleviation of aortic symptoms after specific treatment.

The main aids in separating the two groups are naturally the clinical history with special reference to family history, and failing definite evidence on these points such physical evidence of lues tarda as might justify a clinical diagnosis of congenital syphilis.

Thus we find that in cases 2 and 3 there was a family history of syphilis, and in cases $I$ and 5 a clinical diagnosis of lues tarda was made. In cases 7 and II there was a history of acquired syphilis. It is impossible to group the remaining five cases $(4,6,8,9$, Io) on these lines since no clinical suspicion of syphilis had apparently been aroused. The remaining criteria were intended as guides for the recognition of an aortic lesion in cases of proved congenital syphilis, and are of necessity common to both groups.

It is of interest to note, however, that a clinical diagnosis of an aortic valvular lesion was made in two cases only $(7,9)$, notwithstanding the fact that in the majority of the cases there were gross lesions in the first part of the aorta. It is significant that in these two cases there was definite anatomical evidence of complication by chronic aortic endocarditis. It must be rememered, however, that clinical data were not available in the three cases which were brought in dead $(2,3, \mathrm{II})$.

On the other hand, some degree of coronary occlusion was present in practically all cases. It therefore seems likely that orthodiagraphy and electro-cardiography may be of particular value in establishing a diagnosis.

The aortic lesions in congenital syphilis appear to differ in no way from those seen in the acquired form of the disease, but one is struck by the scanty anatomical evidence of visceral syphilis in the group of heredosyphilitics under review, apart from the aortic manifestations. I have been unable to demonstrate the myo- 


\section{SYPHILITIC AORTITIS IN YOUNG ADULTS}

cardial changes described by Warthin, and am of opinion that these are more easily demonstrated in infantile cases.

In cases I and 3, however, lesions existed which might conceivably be interpreted as being of luetic origin. In the former renal aplasia was present, and according to Hutinel (I922) uni- or bilateral renal aplasia may be caused by the action of specific toxalbumens on the glandular renal elements, leading to arrest of development and to interstitial fibrosis round the embryonic structures. In the latter case one is tempted to regard the condition found in the mesentery at operation as having resulted from rupture of a syphilitic aneurysm in connection with a branch of the superior mesenteric artery.

It is therefore apparent that neither the available clinical nor anatomical data are of service in the five cases of uncertain ætiology among the series under review, and one is forced to rely on the age factor. In this connection a comparison between the average age of previously reported cases of aortitis in lues tarda (autopsy findings), and that of the present series is of some importance.

\begin{tabular}{|c|c|c|}
\hline $\begin{array}{c}\text { GrouP I. } \\
\text { Previously reported. } \\
\text { Congenital. }\end{array}$ & $\begin{array}{c}\text { Group 2. } \\
\text { Present Series. } \\
\text { Congenital. }\end{array}$ & $\begin{array}{l}\text { GrouP 3. } \\
\text { Present Series. } \\
\text { ? Congenital. }\end{array}$ \\
\hline $\begin{array}{ll}\text { Nixon } & \text { (I9II), F. 20 } \\
\text { Turnbull } & \text { (I9II), F. I7 } \\
\text { Turnbull } & \text { (I9II), M. 7 } \\
\text { Von Zetkowsky } & \text { (I9I6), F. I7 } \\
\text { Paul } & \text { (I923), F. I8 } \\
\text { Schulte } & \text { (I930), M. I3 } \\
\text { Martland } & \text { (I930), M. I0 } \\
\text { McDonald } & \text { (I932), M. 9 }\end{array}$ & $\begin{array}{l}\text { (I) M. } 22 \\
\text { (2) M. 2I } \\
\text { (3) F. I9 } \\
\text { (5) F. I9 } \\
-\end{array}$ & $\begin{array}{r}\text { (4) M. } 24 \\
\text { (6) F. } 26 \\
\text { (8) M. } 30 \\
\text { (9) M. } 29 \\
\text { (Io) F. } 30\end{array}$ \\
\hline Average $=\mathrm{r} 4 \mathrm{yrs}$ & Average $=20$ yrs & Average $=28$ yrs. \\
\hline
\end{tabular}

It will be observed that there is a closer approximation between the average ages of Groups I and 2 than between Groups I and 3, but the number of cases is too small to definitely rule out a congenital ætiology in Group 3, more especially since, as was pointed out in my previous communication, cases are on record wherein a confident clinical diagnosis of congenital mesaortitis has been made in patients between twenty-five and thirty-five years of age. 


\section{BRITISH JOURNAL OF VENEREAL DISEASES}

For purposes of comparison, the age distribution of 176 cases of syphilitic aortitis encountered in 7,690 autopsies performed in the Royal Victoria Infirmary, Newcastleupon-Tyne, was investigated, and the result has been

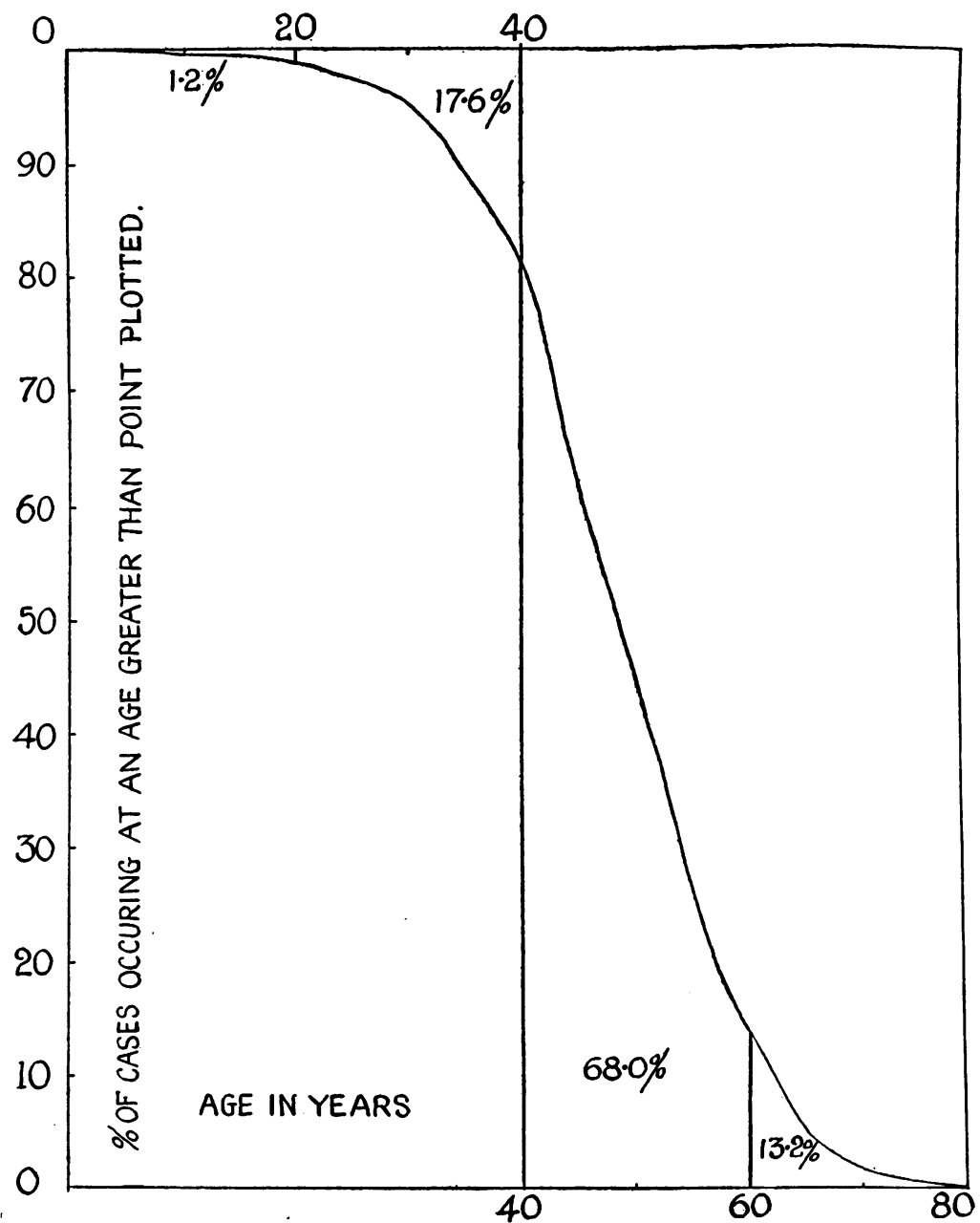

Summation Curve showing Age Distribution of 176 Cases of Syphilitic Aortitis encountered in 7,690 Autopsies (2.3\%).

expressed in graphic form. The case incidence was found to be $2 \cdot 3$ per cent. ; this figure is compatible with those quoted by Carey Coombs (I932) in a review of the available data. It must be remembered, however, that the small number of beds available for children in a large general hospital must be allowed for, but it is 


\section{SYPHILITIC AORTITIS IN YOUNG ADULTS}

unlikely that this correction will materially alter the form of the curve. It will be seen that whereas the main incidence $(68 \cdot 0$ per cent.) occurs between forty and sixty, less than 2 per cent. of cases occur below twenty-one, which is the average age of Groups I, 2 and 3 taken together. It is of some interest to note that the sex distribution in these groups is approximately equal.

According to Coombs, the latent period elapsing between primary infection and the onset of cardiac symptoms is fifteen to twenty-five years, and it therefore seems likely that syphilitic aortitis encountered in the first two and a half decades is of congenital origin. However, a virulent infection as in case II may cause an exception to this rule, and the possibility of primary extragenital infection acquired in infancy must not be overlooked.

On the whole it seems likely that a proportion of the cases in Group 3 are of congenital origin, but a further possibility remains to be considered.

Morhardt (I929) in discussing syphilitic allergy states that there is clinical evidence to prove that the possibility of superinfection shows a progressive increase from the primary to the tertiary period, in which latter cutaneous immunity shows the greatest attenuation. He also points out that syphilitic parents can produce (I) proved heredosyphilitics, (2) dystrophic children whose tissues do not harbour Tr. pallidum and (3) healthy offspring. It may be assumed that either super- or re-infection may take place in the offspring of infected parents, but since a state of syphilitic allergy seems likely to exist in such cases it is at any rate theoretically possible that the course of super- or re-infection may differ profoundly from infection in cases whose family history is negative.

It is therefore suggested that a possible explanation of the occurrence of aortic lesions in a patient whose age falls between the average age distribution of proved congenital and proved acquired infection is that the case may be one of super- or re-infection of an individual whose tissues are allergic to the products of Tr. pallidum.

If it be the case that the tertiary stage of acquired syphilis is the period in which super-infection is most likely, i.e., some fifteen or twenty years after primary infection, it seems reasonable to suggest that a heredosyphilitic after the age of puberty may not only be more 


\section{BRITISH JOURNAL OF VENEREAL DISEASES}

highly susceptible to $\mathrm{Tr}$. pallidum than the descendant of a healthy stock, but also is likely to suffer rapid and progressive aggravation of aortic lesions.

Furthermore, in the case of the descendants of syphilitics who apparently do not harbour $T r$. pallidum, it is also possible that a degree of allergy exists which might accelerate the course of infection and shorten the period elapsing before the appearance of aortic lesions.

It was suggested in my previous communication that there was a marked tendency to spontaneous recovery in congenital syphilitic aortitis, and in this respect there may be a certain similarity between congenital lues and tuberculosis. In pulmonary tuberculous infection of infancy there is a marked tendency to spontaneous recovery, but in those few cases where resistance is low the disease runs a fulminant course. Thus in the majority of cases an immunity to adult respiratory tuberculous infection appears to be conferred, but in the remainder the opposite obtains, and in these allergic individuals pulmonary reinfection shows no spontaneous tendency to resolve, and in the absence of treatment there is active progression of the disease.

From the above considerations it is therefore suggested that the bearing of syphilitic allergy on the problem of aortitis in heredosyphilitics requires careful consideration.

While the number of cases under discussion is too small to allow of generalisations, the practical considerations arising out of the present investigation are twofold. Firstly, one would wish to stress the importance of excluding syphilitic aortitis before making a clinical diagnosis of rheumatic heart disease in young adults. Secondly, since aortitis would appear to be a somewhat commoner manifestation of lues tarda than generally supposed it would seem advisable to proceed cautiously with the administration of organic arsenicals in treating congenital syphilis, even though there are no obvious indications of aortic disease. According to Doumer (I928), such treatment may provoke a violent Herxheimer reaction, and where a degree of coronary occlusion exists a fatal result may ensue.

In this respect it is of interest to note the minute doses of novarsenobillon recommended by Schlesinger (I933) in the treatment of syphilitic aortitis. 


\section{SYPHILITIC AORTITIS IN YOUNG ADULTS}

\section{SUMMARY}

Eleven cases of syphilitic aortitis occurring in patients up to the age of thirty are described. Evidence is adduced that a large proportion of these are of congenital origin or are possibly due to super- or re-infection of allergic heredosyphilitics.

The importance of the differential diagnosis between aortic syphilis and rheumatic heart disease in young adults is stressed, and it is suggested that organic arsenicals be administered with caution in congenital syphilis.

\section{REFERENCES}

Coомвs : Quart. J. Med., I932, 1, I79.

Doumer : Bull. et mem. d. Soc. méd. d. hôp.d. Paris, I928, 1, 853.

Hutinel: Arch.d. Méd.d. Enf., I922, 25, 577.

MARTLAND : Amer. Heart J., I930, 6, I.

McDonald, JR. : Brit. J. Ven. Dis., I932, 8, 263.

MORHARDT: Presse Méd., I929, 21, 340.

Nixon : J. Barts. Hosp., I9II, XUVII., 43.

PAUl: Virch. Archiv., 1923, 59, 240.

Schlesinger: Wien. Klin. Woch., I933, August I8th, ro3o (abs. Brit. Med. J., I933, December 23rd).

Schulte: Zeit.f. Kreislauff., I930, XXII., 753.

Turnbull : Tr. Med. Soc. Lond., I9II, XXXIV., 390.

VoN Zetkowsky: Diss. Inaug. Giessen., I9I6 (ref. Schulte). 